\title{
La arqueología prehistórica y protohistórica española en el siglo XIX ${ }^{1}$
}

\author{
Mariano ayarzagüena Sanz
}

Entre las razones que permiten justificar la elección del tema de la presente tesis hay que citar el hecho de que hoy en día la historia de las diversas disciplinas científicas se reconoce como una parte esencial de las mismas. En el caso de la Arqueología, dado su actual grado de madurez en nuestro país, resultan de particular interés los estudios historiográficos referentes a la historia de las antiguas excavaciones arqueológicas. Entre los beneficios que pueden proporcionar los estudios historiográficos a la Prehistoria y Protohistoria cabe señalar los siguientes:

a) La posibilidad que ofrece la reunión de datos dispersos de antiguas excavaciones, que con los actuales conocimientos permiten establecer una estratigrafía entonces no observada.

b) En algún caso, la recuperación de materiales que se daban por perdidos y que se encontraban arrinconados en estancias de algún Museo, Archivo, Biblioteca, etc.

c) Como en el resto de las ciencias, el aumento de la valoración y prestigio social de la Arqueología al advertir las dificultades que hubo de superar en su día hasta alcanzar el nivel científico actual.

d) $\mathrm{Y}$, por último, y quizás lo más importante, la observación de la génesis de las distintas explicaciones que en su día se elaboraron,

El presente artículo es un resumen de la Tesis Doctoral que, con el mismo título, fue dirigida por el Dr. Eduardo Ripoll Perelló, Catedrático de Prehistoria y Profesor Emérito de la UNED. Fue defendida el 16 de junio de 1992 en la Facultad de Filosofía y Letras de la UNED ante el tribunal constituido por los doctores: Ana Maria Muñoz Amilibia (presidente), María del Rosario Lucas Pellicer (vocal) Ángel Martínez de Velasco (vocal), Gonzálo Ruiz Zapatero (vocal) y Ana Fernández Vega (secretario), obteniendo la calificación de apto. cum laude por unanimidad. 
y que por inercia se han continuado dando por válidas sin conocer los porqués de su difusión en su momento.

Otra de las razones fundamentales por la que también se justifica esta tesis es por el escaso desarrollo que este tipo de investigaciones tiene en nuestro país. Dado que no existen estudios globales que traten con exhaustividad y en conjunto de la Historia de la Prehistoria y Protohistoria españolas del siglo XIX, el marco de referencia ha estado mediatizado habitualmente por una óptica global ajena a la realidad hispana, generalmente anglófila, por razones que expondré más adelante. $Y$ aunque, como es obvio, en muchos aspectos la Ciencia prehistórica española se relacionó con la del resto del continente en el sigloxix, ésta tuvo ciertas peculiaridades que hasta ahora no se han estudiado en profundidad. Una consecuencia de todo esto ha sido el silencio de importantes aportaciones que realizaron los prehistoriadores españoles del siglo pasado, mencionándose casi únicamente el descubrimiento de las pinturas de Altamira. Sin embargo, sus aportaciones son mucho más importantes, como se verá a lo largo del presente artículo.

Los trabajos historiográficos acerca de la Prehistoria han alcanzado un mayor desarrollo en Inglaterra, sobre todo gracias a la labor que Glyn Daniel viene realizando desde mediados del presente siglo. A pesar de que Daniel es un autor que adolece de un claro anglocentrismo, debido a la escasez de este tipo de investigaciones en España, ha sido frecuentemente marco de referencia a nuestros prehistoriadores contemporáneos. Obras suyas de carácter historiográfico y traducidas al castellano han sido: El concepto de prehistoria ${ }^{2}$, Historia de la Arqueología ${ }^{3}$ y Un siglo y medio de Arqueología ${ }^{4}$. No está traducida al castellano su obrita Man Discovers His Past ${ }^{5}$, que a pesar de su brevedad resulta muy útil para adentrarse en la Historia de la Prehistoria.

Recientemente se acaba de publicar en castellano la Historia del pensamiento arqueológico de Bruce G. Trigger ${ }^{6}$, obra claramente influida por

2 Glyn, Daniel, El concepto de Prehistoria, traducción de Ramiro Sánchez Sanz, revisión de Eduardo Ripoll Perelló. Barcelona 1977. Nueva Colección Labor, tercera edición (la primera edición es de 1968).

3 GLyn, Daniel, Historia de la Arqueología. De los anticuarios a V. Gordon Childe. Madrid, Alianza Editorial, 1974

4 GLYN, Daniel, Un siglo y medio de arqueologia. México 1987. Fondo de Cultura Económica. Primera edición en inglés en 1950.

5 Glyn, Daniel, Man Discovers His Past. Londres, Ed. Gerald Duckorth \& Co. Ltd, 1966.

6 Trigger, Bruce G., Historia del pensamiento arqueológico, traducción castellana de ISA. $B E L$, Garcia Trócoli, revisión de Silvia Gili. Barcelona, Editorial Crítica. 1992. Editada en inglés en 1989 por Cambridge University Press. 
Daniel. Este libro introduce plenamente la Historia de la Arqueología dentro del campo de la Historia de la Ciencia, y está llamado a ser el moderno manual al uso que sustituya a los libros de Daniel. Aún así hay que hacer alguna objeción, no dedica ningún espacio a la Prehistoria española, y cuando trata de los primeros descubrimientos de pinturas rupestres se funda en hipótesis erróneas.

Además de la influencia anglosajona hay que mencionar la alemana, como la obra de Herbert Kühn El arte de la época glacial ${ }^{7}$, y la francesa, representada por la "Historia de la Paleontología humana" de Jean-Louis Heim ${ }^{8}$ traducida al castellano y, sobre todo, Origines de l'Archéologie préhistorique en France de A. Laming-Emperaire ${ }^{9}$. Esta obra, aunque se ciñe estrictamente al ámbito de la nación francesa, ofrece un completo estudio acerca de la génesis del concepto mismo de Prehistoria y las distintas corrientes disciplinares existentes durante el siglo XIX. Esta obra tuvo un precedente del mismo autor en la cintroducción" de La découverte du passé ${ }^{10}$.

Por lo que respecta a nuestro país, hasta estos momentos las investigaciones que se han ocupado de la Historia de la Prehistoria y Protohistoria españolas del siglo xix o bien han tratado un tema, autor o yacimiento en concreto, $O$ bien han sido visiones resumidas sobre la Arqueología prehistórica y protohistórica española del siglo xIX. En este último caso los estudios han formado parte de su subapartado dentro de un tema mucho más amplio o han sido comunicaciones o artículos sueltos.

Como visiones resumidas debemos mencionar los diferentes artículos de María Victoria Goberna al respecto " y las "Notas para una historia de la arqueología” de Eduardo Ripoll ${ }^{12}$, además de un breve artículo mío en

\footnotetext{
7 KoHn, Herbert, El arte de la época glacial, traducción de Juan José Utilla (1. ${ }^{a}$ edición en alemán 1965). México, Fondo de Cultura Económica, 1971.

" HEIM, Jean-Louis, "Historia de la Paleontología humana", págs. 267-290, de la obra El hombre: Origenes y evolución, de J. S. Weiner. Barcelona 1980. Ediciones Destino.

9 Laming-Emperaire, A., Origenes de l'Archéologie Préhistorique en France. Paris, Ediciones A. et J. Picard et C., 1964

10 LAMING-EmperaiRE, A., “Introduction», págs. 11-31 de La découverte du passé, progrès récents et techniques nouvelles en préhistoire et en Archéologie. Paris 1952.

Especialmente: Goberna VALENCIA, María Victoria, "La sociedad arqueológica valenciana", Archivo de Prehistoria Levantina XVI, págs. 575-608. Madrid 1981; Goberna VALENCIA, Maria Victoria, "Arqueología y Prehistoria en el País Valenciano; Aportaciones a la historia de la investigación”, en Arqueología del País Valenciano: panorama y perspectivas, anejo de Lucentum. Alicante, Universidad de Alicante, 1985; y GoBeana Valencia, María Victoria, "Los estudios de Prehistoria durante la segunda mitad del siglo xIX y primeros años del $x x$. La obra de Luis Siret", Actas del Congreso Homenaje a Luis Siret (1934-1984), Cuevas de Almanzora (junio de 1984), págs. 28-34. Sevilla 1985.

12 Ripoll Perelló, Eduardo, “Notas para una historia de la arqueología", A distancia, en:
} 
Revista de Arqueología ${ }^{13}$. Ya la más antigua es la descripción de los «Estudios Referentes a la Prehistoria y a la Antigüedad españolas» de Luis Pericot ${ }^{14}$ escrita en la primera mitad del presente siglo.

Mayor número de datos se puede extraer de muchas de las publicaciones españolas del siglo XIX que hacian continua recapitulación sobre las investigaciones realizadas hasta ese momento. El más prolífico en ese sentido fue Juan Vilanova y Piera, quien representó varias comunicaciones a congresos internacionales en los que frecuentemente trató sobre el estado de la Ciencia prehistórica en España, aunque resulta más exhaustivo en su obra Origen, Naturaleza y Antigüedad del hombre ${ }^{15}$ y en el Discurso de ingreso en la Real Academia de la Historia ${ }^{16}$. La memoria del viaje a Dinamarca y Suecia que realizó con Francisco María Tubino en $1869^{17}$ y la obra Geología y Protohistoria ibéricas ${ }^{18}$ escrita conjuntamente con Juan de Dios de la Rada, son también fuentes muy pródigas en datos.

Gran difusor de la Prehistoria fue también el ya mencionado Francisco María Tubino, que en sus Estudios prehistóricos ${ }^{19}$ dio a conocer en España en 1868 las investigaciones prehistóricas que se estaban haciendo, y se habian hecho, en Europa hasta esos momentos. Resulta de obligada referencia su artículo «Historia y progresos de la Arqueología Prehistórica» ${ }^{20}$ para conocer los descubrimientos prehistóricos que se habian realizado en España durante los últimos diez años. De esas fechas es también la

Arqueología hoy, págs., 4-11. Madrid, UNED, junio de 1989. Este mismo autor publicó un resumen sobre Historia de la Prehistoria en: RIPOLL PERELló, Eduardo, “El centenario de la Prehistoria", Ampurias XXVI-XXVII, págs. 333-338. Barcelona 1964-1965.

13 Ayarzagüena Sanz, Mariano, "Orígenes de la Arqueología Prehistórica en España», Revista de Arqueologia, año XI, n. ${ }^{\circ}$ 105, págs., 16-24, enero de 1990.

14 Pericot Garcia, Luis, "Estudios referentes a la Prehistoria y a la Antigüedad españolas", Historia de España. Gran Historia general de los pueblos hispanos, tomo I. Épocas primitiva y romana, págs. 24-30. Barcelona, Instituto Gallach de Libreria y Ediciones, 1934.

15 Vilanova y Piera, Juan, Origen, Naturaleza y Antigüedad del Hombre. Madrid $1872 e$.

16 Vilanova y Piefa, Juan, “Discursos leídos en la Real Academia de la Historia en la recepción pública del Dr. D. .... el día 29 de junio de 1889 ", tema: Protohistoria ibérica. Contestación: Antonio Cánovas del Castillo. Madrid 1889c.

17 Vilanova y Piera, Juan, y Tubino, Francisco Maria, Viaje científico a Dinamarca y Suecia con motivo del congreso internacional celebrado en Copenhague en 1869. Madrid 1871

18 Vilanova y Piera, Juan, y Rada y Delgado, Juan de Dios de la, Geologia y protohistoria ibéricas. Historia general de España escrita por individuos de número de la Real academia de la Historia bajo la dirección de D. Antonio Cánovas del Castillo; $t$ I. Madrid 1892.

19 Tubino, Francisco María, Estudios prehistóricos. Madrid 1868.

20 Tubino, Franciso María, "Historia y progresos de la Arqueologia Prehistórica", Museo Español de Antigüedades 1, págs. 1-21. Madrid 1872a.

21 ASSAS y EREÑo, Manuel de, "Crónica de la provincia de Santander", Crónica general de España XI. Madrid 1869. 
obra de Manuel de Assas Crónica de la provincia de Santander ${ }^{21}$, muy rica en historigrafía prehistórica.

Fue la última década del siglo xIX cuando empezaron a publicarse recapitulaciones entendidas como síntesis crítica de todo lo investigado hasta entonces, gracias a la pluma de Carlos Cañal ${ }^{22}$ y Gabriel Puig y Larraz ${ }^{23}$. A todo ello hay que añadir las memorias que de un periodo muy concreto elaboraron José Ramón Mélida ${ }^{24}$ y Luis de Hoyos Sainz ${ }^{25}$.

Durante el presente siglo se han elaborado algunos trabajos historiográficos con motivo de la investigación de yacimientos específicos. Recordemos, entre otros, el exhaustivo estudio que sobre el Cerro de los Santos realizó José Ramón Mélida ${ }^{26}$; el que verificó José Miguel de Barandiarán sobre la cueva de Lezetxiki ${ }^{27}$, donde incluyó el informe que había escrito Modesto del Valle a finales del siglo pasado; la memoria sobre la Cueva del Parpalló de Luis Pericot ${ }^{28}$; la monografía acerca de Segóbriga, que elaboró Martín Almagro ${ }^{29}$; y el análisis que sobre el $\mathrm{Pa}$ leolítico Medio de Cataluña hicieron E. Ripoll y $\mathrm{H}$. de Lumley ${ }^{30}$, en el que

22 Cañal y Migolla, Carlos, “La prehistoria en España: Notas histórico-bibliográficas», An-

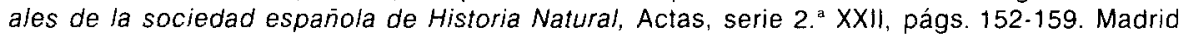
1893

23 Puig y Larraz, Gabriel, “Ensayo bibliográfico de antropología prehistórica ibérica”, Memorias de la Real Academia de Ciencias Exactas, Físicas y Naturales XVII, págs. 683-768. Madrid 1897

24 MÉlida y Alinari, José Ramón, «La Arqueología ibérica e hispano-romana en 1896", Revista de Archivos, Bibliotecas y Museos I, 3. época, n. ${ }^{\circ} 1$, págs. 24-31, enero de 1897.

25 Hoyos SaINz, Luis de, "Anuarios de Bibliografía Antropológica de España y Portugal (1896 y 1897)", Anales de la Sociedad Española de Historia Natural, Memorias XXVI, págs. 243 264. Madrid 1897; Hoyos SaInZ, Luis de, "L'Anthropologie et la préhistoire en Espagne et en Portugal en 1897", L'Anthropologie IX, págs. 37-51. París 1898.

${ }_{26}$ Mélida y Alinari, José Ramón, "Escuituras del Cerro de los Santos. Cuestión de autenticidad", Revista de Archivos, Bibliotecas y Museos IX, 3. época, núms. 8, 9, 10, 11, págs. 140148, 247-255, 365-372, 1 lámina, agosto, septiembre, octubre, noviembre de 1903; MÉLIDA Y AlinARI, José Ramón, "Esculturas del Cerro de los Santos. Cuestión de autenticidad", Revista de Archivos, Bibliotecas y Museos X, 3. época, núms. 1, 8, 9, 10, págs. 43-50, 144-158, 276287, 2 láminas, enero, agosto, septiembre, octubre de 1904; MÉliDa y ALINARI, Jośe Ramón. "Esculturas del Cerro de los Santos. Cuestión de autenticidad", Revista de Archivos, Bibliotecas y Museos XII. 3. época, núm. 1, págs. 37-42, enero de 1905; MÉlida y Alinari, José Ramón, "Esculturas del Cerro de los Santos. Cuestión de autenticidad", Revista de Archivos, Bibliotecas y Museos XIII, 3. ${ }^{a}$ época, núm. 7, págs. 19-38, 2 láminas, julio de 1905.

27 Barandiarán, José Miguel de, “Excavaciones en Aitzbiarte IV (trabajos de 1960)", Munibe XIII, c. 3 y 4, págs. 183-285, Sociedad de Ciencias Naturales Aranzadi. San Sebastián 1961.

28 Pericot Garcia, Luis La Cueva del Parpalló (Gandía), Excavaciones del Servicio de Investigación Prehistórica de la Excma. Diputación Provincial de Valencia. Madrid 1942.

29 Almagro BASCH, Martín, "Segóbriga |. Los textos de la antigüedad sobre Segóbriga y las discusiones acerca de la situación geográfica de aquella ciudad", Excavaciones Arqueológicas en España 123. Madrid 1983.

${ }^{30}$ Ripoll Perello, E., y Lumley, H. de, "El Paleolítico medio en Cataluña", Ampurias XXVI. XXVII, págs. 1-70. Barcelona 1964-1965. 
incluyeron las excavaciones que se habian hecho hasta entonces en yacimientos que contenían niveles de Paleolítico Medio en el área indicada.

Pero la mayor riqueza en historiografía de la Prehistoria española del siglo xIX la ha proporcionado el estudio de Altamira y las disputas que se dieron hasta el reconocimiento de la antigüedad y autenticidad de sus pinturas. Se han descrito exhaustivamente las circunstancias del descubrimiento de Altamira y las mencionadas disputas, aunque tras los recientes estudios historiográficos que se vienen haciendo, tanto en España con en el extranjero, resulta necesario hacer un trabajo con una visión más actual. Algunos de los estudios que se han publicado hasta ahora han sido específicos, como los que han elaborado Benito Madariaga de la Campa ${ }^{31}$. Modesto Sanemeterio Cobo ${ }^{32}$, Miguel Angel García Guinea ${ }^{33}$ $y$, a principios de siglo, Emile de Cartailhac y Henri Breuil ${ }^{34}$. Además, hoy en día toda obra sobre arte rupestre suele ir precedida de un breve estudio historiográfico sobre la historia de los descubrimientos como es el caso de las obras publicadas recientemente por Miguel Angel García Guinea ${ }^{35}$ y Eduardo Ripoll ${ }^{36}$. Este último autor, por otra parte, publicó hace unos años un artículo sobre "Síntesis histórica de los descubrimientos de arte prehistórico y su problemática ${ }^{37}$ ", en el que hace una exposición de la historia de los descubrimientos de arte prehistórico, incluyendo, lógicamente, los realizados en el siglo xIX.

En relación al arte ibérico, Martín Almagro publicó un artículo titulado "Las raíces del Arte ibérico" ${ }^{38}$ que resulta de obligada referencia cuando se quiere empezar a adentrarse en este tema.

31 Madariaga de la Campa, Benito, Hermilio Alcalde del Rio. Una Escuela de Prehistoria de Santander, publicaciones del Patronato de las Cuevas Prehistóricas de la Provincia de Santander. Santander 1972; y MadarIAGa DE LA CAMPA, Benito, "Estudio inicial», Marcelino Sanz de Sautuola. Escritos y documentos, págs. 13-53. Santander Institución Cultural Cantabria, 1976.

32 SANEMETERIO Cobo, Modesto, "Apuntes bibliográficos sobre el descubrimiento de Altamira", Marcelino Sanz de Sautuola. Escritos y documentos, págs. 189-343. Santander, Institución Cultural Cantabria, 1976.

33 García Guinea, Miguel Angel, Altamira y otras cuevas de Cantabria. Bilbao, Ed. Sílex, 1979; García Guinea, Miguel Angel, Altamira. Principio del Arte. Bilbao, E. Sillex, 1980.

${ }^{34}$ CARTAILhaC, Emile de, y Breuil, Henri, La caverne d'Altamira a Santillana près Santander (Espagne). Mónaco 1906.

35 Garcia Guinea, Miguel Angel, "La pintura prehistórica», Historia visual del arte 1. BarceIona, Ed. Vicens-Vives, 1989.

36 Ripoll Perello, Eduardo, “El arte Paleolítico, Historia del Arte 3. Madrid, Ed. Historia 16. 1989.

37 Ripoll Perelló, Eduardo, "Síntesis histórica de los descubrimientos del arte prehistórico y su problemática", Sautuola III, págs. 9-21 (firmado Ampurias, diciembre de 1976). Santander 1982.

38 Almagro Basch, Martín, "Las raíces del Arte lbérico", Papeles del Laboratorio de Arqueologia Valenciana 11, págs. 251-279. Valencia 1975. 
Otro de los campos que ha favorecido la existencia de los estudios historiográficos ha sido el de la biografías y homenajes. La publicación de facsímiles de obras que en su día marcaron un hito en los estudios prehistóricos y protohistóricos, precedidos de una biografía del autor, como es el caso, entre otros, de las Antigüedades prehistóricas de Andalucía, recientemente reeditado con estudio preliminar de Mauricio Pastor Muñoz y Juan Antonio Pachón Romero ${ }^{39}$, permiten conocer mejor no sólo la obra reproducida y la biografía del autor, sino también el ambiente científico en que éste se desenvolvía.

Por otro lado, los homenajes propician los trabajos historiográficos, al facilitar el conocimiento de toda la obra científica del prehistoriador y de sus relaciones con otros investigadores españoles y extranjeros, como es el caso del homenaje que se le tributó a Luis Siret en Madrid en $1985^{40}$ $y$ en Cuevas de Almanzora en junio de $1984^{41}$.

Por último, señalar la importancia que tienen los congresos como el que se llevó a cabo en Madrid en 1988 sobre "Historiografía de la Arqueología y de la Historia Antigua en España (siglos XVII-XX)».

Teniendo en cuenta todo lo que acabo de decir, he vivido los objetivos en global y específicos:

El objetivo global ha sido dar un primer paso en el estudio integral de la Arqueología prehistórica y protohistórica española en el siglo xix, en relación con el ambiente social, cultural y científico de la España de su tiempo.

Para conseguir este objetivo general se plantearon otros, de carácter más específico. Como tales han sido:

- El análisis de los distintos modelos de estudio de los objetos prehistóricos y protohistóricos que existieron en el siglo xIx.

- El establecimiento de una periodización en los progresos de la Ciencia prehistórica, según las etapas que desarrolló desde su nacimiento hasta principios del sigloxx.

- La observación de la relación entre distintas sociedades científicas creadas en ese momento y el impulso que dieron a la Ciencia Prehistórica.

39 Góngora y Martinez, Manuel de, Antigüedades prehistóricas de Andalucia, estudio preliminar por Mauricio Pastor Muñoz y Juan Antonio Pachón Romero. Universidad de Granada, 1991.

40 Ripoll Perelló, Eduardo, "Nota biográfica sobre D. Luis Siret (1860-1934)", en Exposición homenaje a Luis Siret (1860-1934), págs. 6-19. Madrid 1985.

41 Goberna, María Victoria, 1985, 0. c. 
- Investigación de la biografía de aquellas personas que iniciaron las investigaciones prehistóricas en España y sus actividades en este campo. Entiendo que todo dato historiográfico hay que situarlo en el contexto de la persona o personas que en su momento lo protagonizaron; intentar abstraer los datos biográficos, tomando únicamente los contextos histórico, social y cultural, sería tan grave como despreciar esos contextos y utilizar únicamente las biografías.

- Por su proximidad con Portugal, y las posturas paniberistas del siglo $\mathrm{xx}$, se han incluido también las investigaciones prehistóricas portuguesas más importantes de la centuria anterior.

Los datos se han obtenido de bibliotecas, hemerotecas y archivos. Entre las bibliotecas consultadas cabe señalar las siguientes: Biblioteca Nacional; del Museo Arqueológico Nacional; de la Real Academia de la Medicina de Madrid; de la Real Academia de la Historia de Madrid; del Museo de Ciencias Naturales de Madrid; de la Real Academia de Bellas Artes de San Fernando; del Museo Etnológico de Madrid; del Jardín Botánico de Madrid; de la Sociedad Española de Historia Natural; Municipal de Madrid; y del Museo de Prehistoria de Valencia.

Las hemerotecas consultadas fueron: Hemeroteca Municipal de Madrid y Hemeroteca Municipal de Valencia.

Los archivos consultados fueron: del Museo de Ciencias Naturales de Madrid; del Museo Arqueológico Nacional; de Funcionarios de Alcalá de Henares, sección Educación y Ciencia; de la Universidad Complutense de Madrid; del Ministerio de Asuntos Exteriores de Madrid.

El método empleado en la elaboración de la tesis ha sido el ya clásico para este tipo de estudios, y que consta de las siguientes partes:

- La Heurística o búsqueda y conocimiento de fuentes, que comprende la recopilación de los datos obtenidos tras examinar los textos y documentos producidos en el siglo xix, y los que en la presente centuria se han realizado con carácter historiográfico.

- La Crítica, que se ocupa de la ordenación de los datos y comprobación de su autenticidad.

- La Hermenéutica, o correcta interpretación de los textos, para lo que hemos valorado especialmente la terminología usada por los autores de los textos y las diversas corrientes disciplinares que existían en el período de tiempo que aquí se estudia.

- Trabajo de síntesis con la documentación recogida.

- $\mathrm{Y}$, por último, la redacción final de la tesis.

Tras lo cual se han obtenido las siguientes conclusiones: 
$\left.1 .^{a}\right)$ En el siglo XIX se configura la Ciencia prehistórica, con el descubrimiento, en 1862, de un bifaz en San Isidro, por parte de E. de Verneuil, Luis Lartet y Casiano de Prado, y su catalogación en aquellos momentos como de la Edad de Piedra, se puede considerar el inicio en nuestro país de una disciplina que ya estaba gestando desde principios de siglo, tanto en España como en el resto de Europa.

2. $\left.{ }^{a}\right)$ Por el contrario, la Protohistoria tuvo un desarrollo más complejo y difícil. Aunque las leyendas monetales anterromanas se estudiaron ya en la Edad Moderna, el conocimiento de la cultura ibérica no se verificó hasta finales del siglo xix. Hay dos razones fundamentales para este retraso; por un lado la decadencia que experimentó España a mediados del siglo xix en el campo de la erudición antigua; por otro, las falsificaciones del Cerro de los Santos, que en un principio provocaron ciertas reticencias en diversos foros científicos. Sin embargo, gracias a un mayor conocimiento de las culturas prerromanas circunmediterráneas, y a descubrimientos como la necrópolis de Cabrera de Mataró o la Dama de Elche, se pudo tener una idea aproximada de quiénes eran los íberos. De esta forma, el término íbero tiene un significado muy diferente según se encuentre en publicaciones anteriores a la última década del siglo pasado o en las del presente siglo. El estudio de otros pueblos, como los celtíberos, aún se encontraba más atrasado, y poco más se podía decir que los que se podía extraer de historiadores de la Antigüedad.

3. $\left.{ }^{a}\right)$ La Prehistoria pudo alcanzar unas fundamentaciones teóricas cuando fue admitida la alta antigüedad del hombre, mayor de la que tradicionalmente se le atributa. Para ello, en sus primeros años creció junto a las Ciencias Naturales, especialmente la Geología y Paleontologia, ciencias que igualmente se puede considerar que inician su andadura en el siglo $x \mid x$.

4. $\left.{ }^{2}\right)$ Como es lógico suponer, las explicaciones anteriores al nacimiento de la Prehistoria ibérica no desaparecieron de golpe, y permanecieron aún durante cierto tiempo instaladas en la enseñanza oficial y en las instituciones académicas, perdurando hasta los inicios del siglo $\mathrm{xx}$, aunque progresivamente disminuidas. De todas formas, podemos considerar que con el ingreso de Juan Vilanova y Piera en la Real Academia de la Historia en 1989, se rompieron muchas de las trabas que esta ciencia tenía para un normal desenvolvimiento y desarrollo.

5. $\left.{ }^{a}\right)$ De esta manera convivieron a lo largo del siglo $x(x$, al igual que en el resto de Europa, dos paradigmas: el erudito y el naturalista. El paradigma erudito, que sentaba sus bases teóricas en la tradición arqueológica del siglo XVIII, intentaba resolver los problemas planteados mediante la ayuda de la Epigrafía y la Numismática; los seguidores de este 
paradigma mostraron predilección por los estudios protohistóricos y de la España Antigua. El paradigma naturalista, sin embargo, tiene sus fundamentos en la Geología y Paleontología. Dentro de los partidarios de este paradigma, hay que distinguir a los creacionistas, partidarios de la creación del hombre directamente por Dios, y a los evolucionistas, defensores de la evolución desde animales inferiores. Los defensores de este paradigma fueron los más inclinados por los estudios prehistóricos.

6. $\left.{ }^{a}\right)$ Tras generalizarse en Europa la clasificación de las «tres edades» hacia 1860 , pronto se elaboraron otras, como la división de la Edad de Piedra en Paleolítico y Neolítico hecha por John Lubbock en 1865 y la clasificación paleontológica elaborada por Edouard Lartet, las cuales tuvieron amplia y rápida difusión entre los prehistoriadores españoles. Más dificultades en nuestro país tuvo la clasificación de "estaciones-tipo" de Mortillet, que aunque era conocida y utilizada esporádicamente, no gozó en el siglo pasado de la aceptación de las dos anteriores.

7. $\left.{ }^{a}\right)$ En España a lo largo del siglo xIx se da una cierta tendencia hacia el autoctonismo. Había inclinación a pensar que el español había sido conformado con su aspecto y carácter actual desde lo tiempos más remotos. Por ello no es extraño que Vilanova sea el primero en nuestro país en plantear la existencia de un Mesolítico entre el Paleolítico y el Neolítico. Si se tiene en cuenta que la existencia de estas dos “edades" habían sido planteadas en 1865, y en Vilanova propuso su Mesolítico sólo 7 años más tarde, en 1872, se debe admitir que la ruptura de Vilanova con el "hiatus" que entonces se admitía en Europa entre el Paleolítico y el Neolítico fue toda una revolución en el mundo científico internacional. A todo ello se debe añadir la lucha que mantuvo en defensa de una Edad del Cobre anterior a la Edad del Bronce. El fondo ideológico era el mismo, el autoctonismo. Casiano de Prado había apuntado antes que él la posibilidad de la existencia de una Edad del Cobre en España lo que posteriormente apoyaron otros prehistoriadores españoles, como Antonio Machado o Recaredo de Garay, si bien con la diferencia de que mientras Vilanova planteaba la existencia de una Edad del Cobre anterior a la del Bronce, aquéllos pensaban que en Espana se daba una Edad del Cobre en lugar de la del Bronce. Vilanova, al final de sus días, pudo ver sus tesis aceptadas por parte de la comunidad científica internacional. No tuvo la misma suerte en su defensa de la autenticidad y antigüedad de las pinturas de Altamira, que más que admiración despertó recelos y burlas mientras vivó.

8. ${ }^{\text {a) }}$ En relación a este último tema mucho ha sido lo publicado hasta la fecha sobre el descubrimiento de las pinturas de Altamira y disputas posteriores, y en la presente tesis se dedica casi todo un capítulo a las mismas. Quiero insistir en el hecho de que si los prehistoriadores euro- 
peos no quisieron aceptar la autenticidad de las pinturas fue fundamentalmente porque ello parecía demostrar en aquellos momentos las tesis creacionistas defendidas por Vilanova. Por otra parte, si en España tuvo sus contradictores, fueron: por un lado, muchos de los evolucionistas; por otro, los defensores del paradigma erudito, y contrarios, por tanto, a todo lo que suponía la Prehistoria.

9. $\left.{ }^{a}\right)$ El prehistoriador español más importante del siglo pasado fue Juan Vilanova y Piera. Su asidua asistencia a congresos internacionales de Antropología y Arqueología preshistóricas, y a muchos otros, favoreció la llegada a España de las ideas más relevantes que existían en el resto del continente europeo. Sin la presencia de Vilanova, se puede asegurar que la Prehistoria en España habria pasado por unas etapas muy oscuras a lo largo del siglo xix.

10. $\left.{ }^{2}\right)$ Una década antes de morir Vilanova empieza la actividad arqueológica de Luis Siret; en un principio acompañado de su hermano, luego solo. Siret se constituyó en el continuador de la actividad arqueológica peninsular que desempeñó Vilanova hasta su muerte. Por otro lado, Siret en un principio prosiguió la labor que prehistoriadores españoles ya habian acometido con cierto éxito en el levante y sureste español, como Rogelio de Inchaurrandieta, Francisco Cánovas y el propio Juan Vilanova.

$\left.11 .^{a}\right)$ La labor arqueológica de Luis Siret en nuestra península fue de tal magnitud que se le puede considerar como un español más. Fueron varios los prehistoriadores extranjeros que también practicaron investigaciones en nuestro país. Entre ellos hay que destacar a Luis Lartet, Edouard de Verneuil, Edouard Harlé, Emile Cartailhac; y en las islas Canarias a Sabin Berthelot y a René Verneau. En el campo de la Protohistoria fue decisiva la intervención de Emilio Hübner y Jorge Bonsor.

12. $\left.{ }^{2}\right)$ La división que he hecho de los estudios prehistóricos del siglo xIx si bien es, al igual que la mayor parte de las clasificaciones al uso, de carácter convencional, pues los límites que separan una etapa de otra no están claramente definidos, no obstante, se basan en elementos objetivos que permiten diferenciar unas de otras. Estas etapas son: a) antes de 1860 , b) $1861-1865$, d) $1873-1878$, e) $1879-1885$, f) $1886-1893$ y g) 1863-1900.

Para concluir voy a exponer las notas más destacas de cada una de estas etapas:

a) Antes de 1860:

La Ciencia prehistórica aún no había tomado carta de naturaleza, aunque se pueden citar prospecciones de yacimientos y la recolección de 
útiles prehistóricos por parte de Casiano de Prado, tanto en algunas cuevas como en San Isidro.

Los monumentos megalíticos, los cuales eran atribuidos a los celtas, se empiezan a estudiar de forma sistemática por arqueólogos de la talla de Manuel de Assas. La razón para el surgimiento de estos estudios se encuentra en la búsqueda de los orígenes de la identidad nacional, en el pleno desarrollo del Romanticismo. Los descubrimientos más importantes corresponden a Cueva Menga y dolmen de Dílar, ambos en la provincia de Málaga; varios dólmenes en Extremadura; el dolmen de Eguilaz en Álava; y los monumentos megalíticos de las islas Baleares, éstos magníficamente estudiados por Juan Ramis.

El vascoiberismo, defendido por Humboldt a principios de siglo, se mantuvo en plena vigencia, sin apenas contradictores, pues aún la Arqueología no habia tomado parte en el debate. Ya en la segunda mitad del siglo fue perdiendo fuerza, aunque de una manera más o menos matizada ha llegado hasta nuestros días.

En esta etapa nace la Sociedad Numismática Matritense, gracias a la labor de Castellanos de Losada. Esta sociedad sería el germen de la futura Real Academia de Arqueología y Geografía del Príncipe Alfonso, que tuvo una vida muy breve, al quedar cercenada su existencia años más tarde con la Revolución del 68 y el problema de competencias que mantuvo con la Real Academia de la Historia.

b) Etapa 1861-1865:

En esta etapa la Prehistoria empezó a ser reconocida oficialmente en España aunque en ámbitos muy restringidos. También en Europa eran muy pocos los que habían mostrado interés por los estudios que habían realizado Jacques Boucher de Perthes, MacEnery y Schmerling antes de 1860 , siendo a partir de ese año cuando la Prehistoria empezó a ser una disciplina científica.

En España destacó la actividad de Casiano de Prado y el primer reconocimiento en 1862 de un yacimiento prehistórico, San Isidro, gracias a Luis Lartet, F. E. Verneuil y al propio Casiano de Prado. Este prehistoriador, al dar a conocer su descubrimiento dos años más tarde, utilizó la clasificación paleontológica de Eduardo Lartet. A partir de esos momentos Casiano de Prado se convirtió en el impulsor más decidido de esta nueva ciencia. Otros prehistoriadores españoles que se iniciaron en esta etapa fueron Juan Vilanova, Francisco M. ${ }^{a}$ Tubino y Antonio Machado. En Portugal, Francisco Antonio Pereira de Costa y Carlos Ribeiro empezaron en 1863 a explorar el famosísimo yacimiento de Cabeço de Arruda. El yacimiento lo dio a conocer el primero de ellos en 1865. 
Luis Lartet volvió a España en 1865, esta vez a explorar diversas cuevas alavesas y de la Sierra de Cameros. En esta zona excavó Cueva Lóbrega, importante yacimiento riojano. También llegaron a la península los ingleses Falconer y Busk, quines tras inspeccionar los yacimientos de Gibraltar que estaban tomando gran importancia, visitaron a varios naturalistas hispanos, con el fin de animarlos hacia las investigaciones prehistóricas. Uno de los cráneos estudiados fue el que hoy sabemos que pertenece a la raza de Neanderthal y que se encontró en 1848, aunque por la falta de conocimientos prehistóricos en aquellos momentos, tuvo que esperar 20 años para empezar a valorarse convenientemente. Este cráneo fue uno de los primeros neanderthales del mundo en recogerse.

Paul Broca se interesó por los estudios antropológicos vascos, motivando a su amigo Pedro González de Velasco para que creara la Sociedad Antropológica Española, institución que tuvo siempre a la Prehistoria por norte.

En relación a los estudios protohistóricos debe destacarse que fue en estos momentos cuando empezó a tomarse en cuenta el yacimiento del Cerro de los Santos, aunque atribuyéndole José Amador de los Ríos una cronología visigoda en Epigrafía y Numismática lo más importante fue la llegada a España de Emilio Hübner, quien se puso en contacto, entre otros, con Manuel Rodríguez de Berlanga, iniciándose así una fructífera amistad.

c) Etapa 1866-1872:

En 1866, cuando muere Casiano de Prado, la Prehistoria se encontraba a punto de realizar su despegue en España. Casiano de Prado se había dedicado hasta los últimos días de su vida a los estudios prehistóricos: la muerte le sobrevino tras visitar Cerro Muriano, donde parece que llegó a apreciar su importancia prehistórica.

A la muerte de Casiano del Prado, Juan Vilanova continuó con la investigación de San Isidro. A este respecto, fueron muy importantes las visitas que realizó Vilanova con sus alumnos a San Isidro al acabar cada curso de su cátedra en El Ateneo, donde se formaron muchos prehistoriadores españoles del siglo pasado. Además, en el verano de $1866 \mathrm{em}$ pezó Vilanova a propectar en cuevas valencianas, y con ello se inició un nuevo rumbo en la Prehistoria española. Ese mismo año excavó cuevas de la importancia del Parpalló o Cova Negra. Fruto de las investigaciones que había realizado, en 1872 publicó Origen, naturaleza y antigüedad del hombre, primera obra española de conjunto que trata sobre la Prehistoria de todo el Estado. 
Otra circunstancia que me ha llevado a iniciar la etapa en 1866 es que a partir de ese año la Prehistoria empezó a ser reconocida en España dentro del ámbito científico y también en el popular. En otoño de 1867 aparece en castellano por primera vez la palabra "prehistoria" de la pluma de Francisco María Tubino, cuya discusión sobre lo acertado de la denominación tanto ha dado que hablar. El término sale de la pluma de Tubino en su periódico La Andalucia de Sevilla. Si tenemos en cuenta que, según la literatura al uso, en Inglaterra dicha palabra apareció por primera vez en 1851 de la pluma de Daniel Wilson, se puede observar el retraso con que llegaba el concepto de esta disciplina a nuestro país.

Esta corta etapa supuso una auténtica revolución científica en la Ciencia prehistórica española por la generalización de los conocimientos prehistóricos, la cantidad y clidad de los descubrimientos y por el deseo de conocer qué hay de cierto sobre la incipiente Ciencia prehistórica. Las discusiones en pro y en contra de la nueva disciplina se llevan a nivel popular. Las charlas que al respecto inició Vilanova en el Ateneo Científico y Literario de Madrid y Francisco María Tubino en la Sociedad Económica Matritense despertaron un gran interés y las salas de conferencias se abarrotaron. Todo lo que acabo de exponer no quiere decir, por supuesto, que la Prehistoria fuera unánimemente aceptada, ni que lograra ingresar de forma oficial en el mundo académico, ni tampoco que alcanzara el rango que estaba adquiriendo en el resto de los países europeo. Aún así, si miramos cuál era la situación de la Prehistoria en España en 1866 y cuál en 1872, se puede decir que pocas ciencias han alcanzado un desarrollo de tal magnitud en tan poco tiempo.

Otros prehistoriadores importantes de estas fechas fueron Manuel de Góngora, que publicó en 1868 Antigüedades Prehistóricas de Andalucia, maravilloso libro en el que dio a conocer sus descubrimientos en la Cueva de Albuñol y William Macpherson excavó la Cueva de la Mujer.

Además, en 1867 se creó definitivamente el Museo Arqueológico Nacional, y en 1871 la Sociedad Española de Historia Natural y la Sociedad Antropológica Sevillana. Todos ellos impulsaron los estudios prehistóricos. Al mismo tiempo, en 1872 se iniciaba la andadura de la revista Museo Español de Antigüedades en la que se publicaron interesantes artículos sobre Prehistoria.

En Protohistoria se debe destacar que en este período es cuando el Museo Arqueológico Nacional formó una Comisión con el fin de traer esculturas y hacer excavaciones en el Cerro de los Santos. Por otra parte, Rada y Delgado acometió el famoso viaje en la Fragata Arapiles, en el que entró en contacto con las culturas mediterráneas protohistóricas, aun- 
que todavía no tuvo suficientes elementos de juicio para poder catalogar los objetos que de esa época aparecian en España.

d) Etapa 1873-1878:

Tras el año vertiginoso de 1872, en que las publicaciones y estudios prehistóricos tuvieron un gran desarrollo en nuestro país, éstos entraron en una fase de decadencia, no sólo en España, sino también en Europa. No existe una única razón para este hecho: a) por un lado hay que decir que la Prehistoria había sido una moda, que como tal tenía que pasar, para seguir posteriormente con un desarrollo normal; b) también se debe relacionar con el informe que emitió Rodolfo Virchow en 1872 acerca de los restos humanos encontrados en el valle del Neander, Virchow, frente a los que creían que dichos restos suponían pruebas incontestables de la existencia de hombres conjuntamente con animales fósiles, como así era, defendió que tales restos pertenecian a un hombre moderno que había padecido una artritis deformante; y c) por último, no hay que olvidar a todas aquellas fuerzas conservadoras que desde un principio se mostraban con recelos acerca de la Prehistoria, con gran temor por su ortodoxia religiosa a quienes la publicación en 1871 de La descendencia humana por parte de Darwin les debió afectar especialmente.

En España se notó en la disminución de las publicaciones que trataban sobre Prehistoria y en la defección, al menos en parte, de algunos de sus antiguos defensores. Así tenemos el caso de Fernando Fulgosio, defensor de la alta antigüedad del hombre de 1868, y sin embargo en 1872, cuando trató de la Prehistoria, desdeño la Geología, y dio, consiguientemente escasa antigüedad a los restos prehistóricos. De todas formas, en nuestro país se siguieron realizando investigaciones prehistóricas, existiendo corporaciones y sociedades, como la Sociedad Española de Historia Natural, la Sociedad Española de Antropología o la Sociedad Arqueológica Valenciana, en las que la Prehistoria siguió teniendo cierta acogida.

En relación a la Protohistoria hay que mencionar el discurso de entrada en la Real Academia de la Historia de Juan de Dios de la Rada y Delgado en 1875. El tema del mismo fue las esculturas del Cerro de los Santos. Aunque Rada tuvo la mala fortuna de basar sus argumentos en la esculturas falsas.

e) Etapa 1879-1885:

En esta etapa volvió a darse un nuevo impulso a la Prehistoria. Por otra parte, en el sureste empezaron las prospecciones de los hermanos Siret. A partir de 1879 los estudios prehistóricos en España se generalizaron, alcanzando una mayor relación con los descubrimientos que se 
hacían en esos momentos en Europa. Se fija esta nueva etapa en los estudios prehistóricos españoles por las siguientes razones:

1. En el año 1880 Marcelino Sanz de Sautuola publicó sus famosos "Apuntes...". Por primera vez se dataron como paleolíticas unas pinturas rupestres. El descubrimiento y defensa de la autenticidad y antigüedad de las pinturas de Altamira por parte de Marcelino Sanz de Sautuola, y su valedor Juan Vilanova, supuso un hito en los estudios prehistóricos en nuestro país.

2. Se empezó a utilizar, de forma sistemática en España, la clasificación arqueológica de "estaciones-tipo" establecida por Mortillet a finales de los años 60 .

3. ${ }^{\text {a }}$ En 1880 se llevó a cabo el IX Congreso de Antropología y Arqueología Prehistóricas en Lisboa, que tuvo gran trascendencia y repercusión en España. En el mismo participó Vilanova, con una destacada presencia por la variedad de teorías que defendió en dicho Congreso.

4. Resultan palpables los progresos habidos en los estudios geológicos, con la consiguiente trascendencia en la Prehistoria, Vilanova empezó a conectar con las corrientes más progresistas en geología, abandonando el plutonismo.

5. Por último, se debe lamentar el abandono de la Prehistoria que hizo Francisco María Tubino a partir de 1879.

f) Etapa 1886-1893:

El año de 1886 es frecuentemente recordado por haber sido aquel año el de las disputas en la Sociedad Española de Historia Natural, sin embargo, pienso que aún más importante fue el hecho de que en ese año el nuevo director de la Real Academia de la Historia, Antonio Cánovas del Castillo reconociera a la Prehistoria de un modo oficial. De esta forma la Prehistoria comenzó a entrar en España dentro del campo académico. El definitivo afianzamiento del belga Luis Siret como gran prehistoriador nacional y el nacimiento de un fuerte grupo arqueológico en Andalucía, sobre todo, en Sevilla, marcan una etapa que verá su fin con la muerte de Vilanova en 1893.

La importancia que tomó la Prehistoria en nuestra península tras el Congreso de Lisboa de 1880 mereció que una personalidad como la de Émile Cartailhac se desplazara a nuestro país con el fin de estudiarla. Parece que en un principio el objetivo de Cartailhac consistía únicamente en el estudio de la Prehistoria portuguesa, pero que tras una conversación con Salvador Sanpere, quien le comentó la existencia de una especificidad 
cultural peninsular en tiempos prehistóricos, se decidió por incluir en su estudio el ámbito geográfico de España y Portugal. El resultado de este viaje de Cartailhac quedó reflejado en el libro Les Ages preshistoriques de l'Espagne et du Portugal con prólogo de Quatrefages, donde ofreció el autor una visión global de la Prehistoria ibérica. La obra no fue tan exhaustiva como la de Vilanova de 1872 o la de Vilanova y Rada de 1892, pero ofrecía la oportunidad de observar la visión que sobre la Prehistoria española existía en París, capital de la Prehistoria mundial en esas fechas. En 1892 volvió a publicar un interesante estudio sobre los monumentos megalíticos de una parte del territorio español, las Baleares, con el fin de defender sus tesis difusionistas.

\section{g) Etapa 1893-1900:}

La muerte de Vilanova en 1893 privó a la humanidad de uno de los prehistoriadores más importantes de su tiempo y, sin duda, del prehistoriador español más destacado del siglo xIx. Para mayor desgracia de la Ciencia prehistórica española, desapareció sin dejar discípulo que le sustituyera. Esto no quiere decir que no hubiera quien realizara estudios prehistóricos de envergadura, pero, cuando éstos se llevaron a cabo, fue dentro de un ámbito más local, sin esa trascendencia internacional que aportaba Vilanova, fruto de los diferentes congresos a los que asistía en el extranjero. Por ello hay que esperar a la segunda década del presente siglo para que la Prehistoria en España vuelva a emerger con fuerza.

Como excepción del panorama expuesto sólo se puede citar a Luis Siret, quien venía practicando excavaciones arqueológicas en el área del Sureste desde 1880 , pero que partir de principios de los noventa, viajó por toda la Península, en compañia de su capataz Flores, estudiando todos los yacimientos prehistóricos españoles de importancia. Se puede considerar a Siret como continuador de la labor de Vilanova en su aspecto de divulgador de la Prehistoria española y por su relación con los prehistoriadores europeos, Siret expuso los resultados de la Ciencia prehistórica española en los diversos congresos internacionales que se llevan a cabo en el extranjero, de forma parecida a como lo había hecho Vilanova, y resulta significativo que, el mismo año de la muerte de Vilanova, Siret publique L'Espagne prehistorique. Sin embargo, no mantuvo las tesis en Prehistoria que defendia Vilanova, sino que estaba más en contacto con las que se encontraban de moda en Europa, esto no supuso siempre, por el contrario, un avance para la Prehistoria en todos los casos. El progresivo abandono del interés en España por la Prehistoria se refleja en su nula asistencia al Congreso internacional de Antropología y Arqueología Prehistórica de Moscú de 1892, o en la escasísima representación que asistió a la de París de 1900, a la que sólo acudieron los 
canarios Gregorio Chil y Naranjo y D. Ripoche y el vasco Telesforo de Aranzadi, sin duda por la relación de estrecha amistad que mantenían con René Vernau, a la sazón presidente del Congreso.

También se nota la desaparición de Juan Vilanova en las publicaciones que sobre Prehistoria se hicieron inmediatamente después en nuestro país. Se observa en algunas revistas, como en el Boletín de la Real Academia de la Historia, que tras la muerte de Vilanova, poco a poco empezaron a desaparecer los artículos que trataban sobre Prehistoria, haciéndose éstos muy raros a finales de siglo. De esta manera, como norma general, se puede decir que con la muerte de Vilanova se abrió una gran crisis en la Prehistoria española que duró 20 años.

Los prehistoriadores españoles de finales de siglo xIX fueron, sin embargo, ya mucho más maduros que la primera generación de prehistoriadores representada por Vilanova, pues se diferenciaron con respecto a los anteriores en algo fundamental; éstos tuvieron que afrontar los problemas por primera vez, mientras que los que empezaron a finales de siglo ya tenían por punto de referencia a otros que ya lo trataron previamente. A finales de siglo ya se tomaba en cuenta la Prehistoria a todos los niveles, y por ello no podía faltar su tratamiento de forma seria y actual (para aquellos momentos) en ninguna de las grandes enciclopedias que entonces se realizaron.

Junto a la zona del Sureste en que, gracias a Luis Siret, la Prehistoria gozaba de un aceptable desarrollo, se debe destacar la labor que en Sevilla continuaba realizando la sección sevillana de la Sociedad Española de Historia Natural, y el Ateneo y la Sociedad de Excursiones de Sevilla, en cuyo seno escribieron importantes obras Feliciano Candau y Carlos Cañal; además, en el bajo Guadalquivir continuó sus excavaciones Jorge Bonsor, quien hizo importantes descubrimientos prehistóricos.

En Protohistoria fue sobre todo gracias a personalidades de la talla de Jorge Bonsor, Pierre Paris, Arthur Engel y José Ramón Mélida por las que se llegó a conocer el mundo prerromano peninsular, que hasta aquellos momentos era aún más desconocido que el prehistórico. En un ambiente científico en el que cada vez con mayor seguridad se iba comprendiendo el mundo cultural circunmediterráneo, el descubrimiento de la Dama de Elche en 1897 resultó definitivo para el reconocimiento del arte ibérico.

\section{SUMMARY}

This thesis aims to take the first step in the integral study of Spanish prehistoric and protohistoric archaeology in the XIX century, in relation to 
the social, cultural and scientific milieu in Spain at the time. In the process various more specific pieces of work have been carried out among which it is possible to highlight the following:

- The analysis of the various study models for the prehistoric and protohistoric objects which existed in the XIX century.

- The establishment of a periodisation in the development of prehistoric Science, according to the stages which developed from its birth up until the beginning of the XX century.

- The observation of the relationship between different scientific societies create at this point in time and the impetus they gave to Prehistoric Science.

- Research into the biographies of those people who initiated research into prehistory in Spain and their work in this field. The work carried out by foreign prehistorians and protohistorians such as Vernau, Harlé, Cartailhac, Siret, Paris, Engel, Hübner and Bonsor, in Spain, has been particularly valued.

- The most important Portugueses research into prehistory of the previous century has also been included due to its proximity with Spain and the pan-iberian stance in the XIX century.

Among the most important conclusions one must point out that prehistoric Science has taken shape in the XIX century. The discovery in 1862 of the flint axe of San Isidro by Verneuil, Luis Lartet and Casiano de Prado, and it being catalogued at that time as being from the Stone Age, may be considered the commencemet in Spain of a discipline which had already been evolving since the beginning of the century, both in Spain and in the rest of Europe. One aspect to point out is the trend towards autochthonism on the part of the Spanish prehistorians, who avoided the existence of a "hiatus", defending the existence of periods such as the "Mesolithic" period and the "Copper Age". 